\title{
Experience with Coeliac Axis Compression Syndrome
}

\author{
A. J. EDWARDS,* M.Sc., M.CH., F.R.C.s. ; J. D. HAMILTON,† M.B., B.S., M.R.C.P. ; W. D. NICHOL, $\ddagger$ M.B., CH.B., F.F.R. \\ G. W. TAYLOR, $\$ M.S., F.R.c.s. ; A. M. DAWSON,\| M.D., F.R.C.P.
}

British Medical fournal, 1970, 1, 342-345

Cummary: Seven patients with "coeliac axis compres$\checkmark$ sion syndrome" are reported. Five were treated surgically, but only two did well. A survey of 200 healthy adults showed epigastric bruits in $6.5 \%$; only one of these had dyspepsia, though dyspepsia was present in $12.5 \%$ overall.

Caution is urged in attributing a causal relationship between coeliac axis compression and pain and in proceeding to arteriography when compression is suspected on clinical grounds.

\section{Introduction}

Recent series of case reports from three American (Snyder et al., 1967; Marable et al., 1968; Lord et al., 1968), one Finnish (Harjola and Lahtiharju, 1968), and one Israeli (Deutsch, 1968) centres have defined a "coeliac axis compression syndrome" in which abdominal pain is associated with the partial obstruction of the coeliac axis artery by the median arcuate ligament of the diaphragm or a fibrotic coeliac ganglion. Surgical release of this obstruction has resulted in abolition or major amelioration of symptoms in most of the 61 documented cases reported in the literature. The acceptance of this syndrome as an entity has been challenged (Drapanas and symptomatology of the condition is rather vague and highly subjective. Drapanas and Bron (1966) also reported a high incidence of psychological disturbances in persons with the syndrome. They urged the necessity for careful blood flow studies in these patients before the syndrome could be accepted or proved.

Conscious, therefore, of the possible lack of relationship between the vascular and clinical features of such patients, we have studied seven patients who have apparently fulfilled accepted criteria. Since an epigastric bruit is the most important physical sign leading to the diagnosis of the syndrome, we have ascertained the incidence of epigastric bruit and dyspepsia in 200 volunteers, of the age group suggested by Marable et al. (1968) as the most typical of the syndrome, in order to assess the importance of this clinical sign.

\section{Patients and Surgical Procedures}

Seven patients (five women and two men) aged 18 to 50 years presented histories of 16 to 204 months (Table I). They all had, at one time, epigastric bruits that prompted angiographic study by percutaneous transfemoral retrograde aortography with selective catheterization of the superior mesenteric artery.

TABle I.-Clinical Details and Results of Surgery in Seven Cases of Coeliac Compression Proved by Arteriography

\begin{tabular}{|c|c|c|c|c|c|}
\hline Case No. & Sex and Age & Dominant Symptom & $\begin{array}{l}\text { Length of History } \\
\text { (months) }\end{array}$ & Bruit & Result of Surgery \\
\hline 1 & $\mathrm{~F} 18$ & Pain & 16 & Disappeared when the artery occluded & $\begin{array}{l}\text { Permanent obstruction of coeliac axis. } \\
\text { Ileosplenic venous graft with doubtful } \\
\text { fow. Symptom-free }\end{array}$ \\
\hline $\begin{array}{l}2 \\
3 \\
4 \\
5\end{array}$ & $\begin{array}{l}\text { F24 } \\
\text { F24 } \\
\text { F44 } \\
\text { M50 }\end{array}$ & $\begin{array}{l}\text { Pain } \\
\text { Pain } \\
\text { Pain } \\
\text { Pain, diarrhoea, weight loss }\end{array}$ & $\begin{array}{r}30 \\
54 \\
60 \\
204\end{array}$ & $\begin{array}{l}\text { On inspiration } \\
\text { Disappeared on inspiration } \\
\text { Disappeared on inspiration } \\
\text { Disappeared on inspiration }\end{array}$ & $\begin{array}{l}\text { now. Symptom-tree } \\
\text { Symptom-free } \\
\text { Return of many other symptoms } \\
\text { Return of same symptoms } \\
\text { Stenosis relieved but symptoms un- }\end{array}$ \\
\hline $\begin{array}{l}6 \\
7\end{array}$ & $\begin{array}{l}\text { F27 } \\
\text { M23 }\end{array}$ & $\begin{array}{l}\text { Pain, diarrhoea, weight loss } \\
\text { Pain }\end{array}$ & $\begin{array}{r}24 \\
168\end{array}$ & $\begin{array}{l}\text { Disappeared on inspiration } \\
\text { No change with respiration }\end{array}$ & $\begin{array}{l}\text { changed. Popliteal embolus } \\
\text { Refused operation } \\
\text { Advised against surgery }\end{array}$ \\
\hline
\end{tabular}

Bron, 1966). In the first place it runs contrary to the view that the equivalent of more than one of the visceral arteries need to be occluded before mesenteric ischaemia is provoked (Rob, 1967; Dick et al., 1967). Secondly, typical angiographic appearances may be shown in asymptomatic people (Sutton, 1967), and Drapanas and Bron (1966) noted such a picture in $13 \%$ of all selective coeliac and mesenteric arteriograms performed at their centre over a four-year period. Thirdly, the

\footnotetext{
* Senior Lecturer in Surgery, St. Bartholomew's Hospital, London E.C.1

Consultant Surgeon, Hackney Hospital, London E.9.
†Research Associate, St. Bartholomew's Hospital, London E.C.1. Present
address : Department of Medicine, McMaster address: Department of Medicine, McMaster University, Hamilton, Ontario, Canada.

¥Consultant Radiologist, St. Bartholomew’s Hospital, London E.C.1.

SProfessor of Surgery, St. Bartholomew's Hospital, London E.C.1.

||Physician, St. Bartholomew's Hospital, London E.C..1.
}

From these cases we would summarize the syndrome in the following manner.

Symptoms.-(1) Epigastric pain or discomfort related more to posture and activity than to food. (2) Symptoms often relieved by recumbency. (3) Psychological element often suspected.

Signs.-(1) Predominately young women. (2) Usually leptosomatic in habitus. (3) There is an epigastric bruit which is altered by position and respiration. (4) Lateral aortography shows anterior compression of the coeliac axis. Selective catheterization of the coeliac axis is not possible, but selective superior mesenteric arteriograms show, in the anteroposterior view, good collaterial flow in the coeliac axis branches via the pancreaticoduodenal vessels.

Laparotomy was conducted in five of the cases by way of 
an upper paramedian incision, when good access was obtained through the gastrohepatic omentum. In all cases the coeliac axis was found to be compressed by fibromuscular tissue associated with the median arcuate ligament of the diaphragm and intermingled with strands of the coeliac plexus. Contrary to previous statements by Snyder et al. (1967) it was often difficult to say which component of this complex was causing the stenosis. The coeliac artery was freed from constriction by incision along its ventral aspect and no attempt at coeliac neurectomy or ganglionectomy was made. In one case an arterial reconstruction had to be performed. The excised tissue appeared similar in histology to that described by Harjola and Lahtiharju (1968), and comprised fibrous tissue, striated muscle fibres, and autonomic nerves with perineural and occasionally intraneural fibrosis.

Intraoperative studies of blood flow were made in four cases by means of a Nycotron electromagnetic flow meter, and changes of flow in the hepatic or splenic arteries with respiratory excursion were noted. The variation of the obstructive effect of the diaphragm on the coeliac axis with natural respiration when upright may not be identical with that produced by mechanical inflation of the lungs under operative condition, so that caution in interpretation of the results is mandatory.

\section{Case Histories}

Case 1.-Epigastric cramp-like pain was associated with nausea and became unrelated to food, being relieved only by recumbency. Two months after an angiogram had shown constriction of her coeliac axis the patient's symptoms became worse, her epigastric bruit disappeared, and repeat angiography showed total occlusion of the coeliac axis. At laporotomy this was found to be bound down by the median arcuate ligament and to be lumenless. Mean pressure in the hepatic artery (as measured with a transducer) was $60 \mathrm{~mm} . \mathrm{Hg}$, while the brachial mean pressure was $83 \mathrm{~mm} . \mathrm{Hg}$, a gradient of $23 \mathrm{~mm} . \mathrm{Hg}$, which is comparable to that of other reported cases (Lord et al., 1968; Harjola and Lahtiharju, 1968). A vein graft was inserted between the splenic and left common iliac arteries, in which a systolic flow of $100 \mathrm{ml} . / \mathrm{min}$. and a mean flow of $30 \mathrm{ml} . / \mathrm{min}$. were recorded. She has remained well and symptom-free in the 18-month follow-up; her case has been reported elsewhere in greater detail (Edwards, 1969).

Case 2.-Epigastric pain in this Iranian woman occurred only with recumbency and was worse on deep inspiration. An epigastric bruit was audible only during inspiration. Intraoperative flow measurement (Fig. 1) showed a reversal of blood flow in the hepatic artery during deflation of the lungs. During inflation mean forward flow was $20 \mathrm{ml} / \mathrm{min}$. (from aorta to liver) while during deflation it was $34 \mathrm{ml} . / \mathrm{min}$. in the opposite direction (pancreaticoduodenal to splenic). After decompression the flow was entirely forward, varying from 14 to $20 \mathrm{ml}$./min. with phases of pulmonary inflation. She has remained free from signs and symptoms for 14 months.

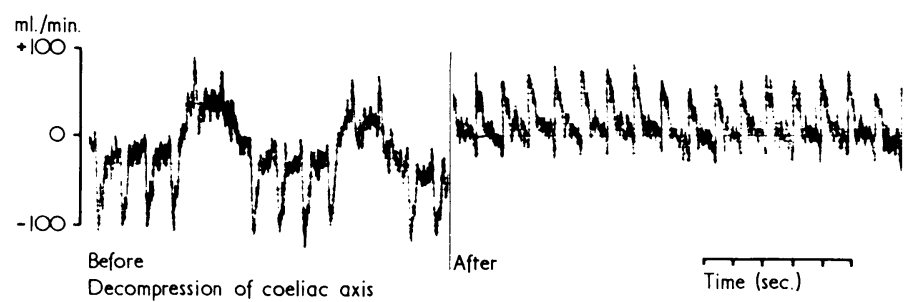

FIG. 1.-Case 2. Operative blood flow studies showing reversal of blood flow in hepatic artery during deflation of lungs. No reverse of flow after decompression.

Case 3.-Epigastric pain was mainly nocturnal, postcibal, and worse on deep inspiration. Delayed gastric emptying was found on the first two of her three barium meals. At operation the mean blood flow (Fig. 2) in her splenic artery was reduced from $57.5 \mathrm{ml}$. during quiet respiration to $40 \mathrm{ml} . / \mathrm{min}$. during sustained inflation, withour detectable change in pulse or blood pressure. On deflation of the lungs the flow was zero. It may be supposed that the cardiac output was not altered by these procedures, so that the greater flow during quiet respiration probably represents the hyperaemic response to intermittent arterial occlusion. Following decompression of the coeliac axis there remained a $25 \%$ narrowing of its diameter $(56 \%$ of its area). The maximum diameter was 4 $\mathrm{mm}$. and the diameter at the residual constriction $3 \mathrm{~mm}$., while the splenic and hepatic arteries both measured $5 \mathrm{~mm}$. and the left gastric $2 \mathrm{~mm}$. She remained symptom-free for two months, but thereafter developed bizarre symptoms associated with depression. Repeat aortogram was normal and catheterization of the coeliac axis easy. There was no sign of residual stenosis.
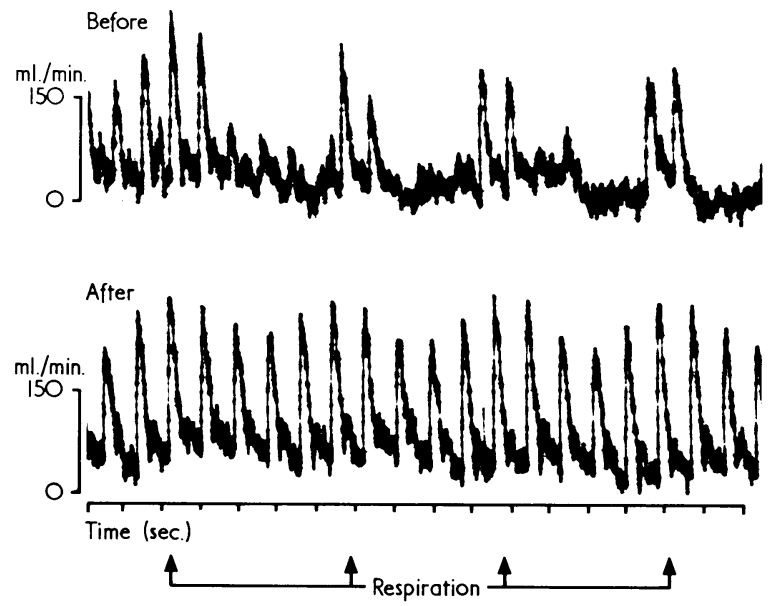

Fig. 2.- Case 3. Operative blood flow studies. Note decrease in blood flow in splenic artery during sustained inflation of lungs.

Case 4.-This woman's abdominal pain was worse with specific foods and relieved by rest. Her bruit disappeared on inspiration. Operative decompression of her coeliac axis afforded her only one week's respite from symptoms. Intraoperative flow studies were not performed.

Case 5.-This 50-year-old man had a 15-year history of dyspepsia and had had two gastric ulcers that healed medically.

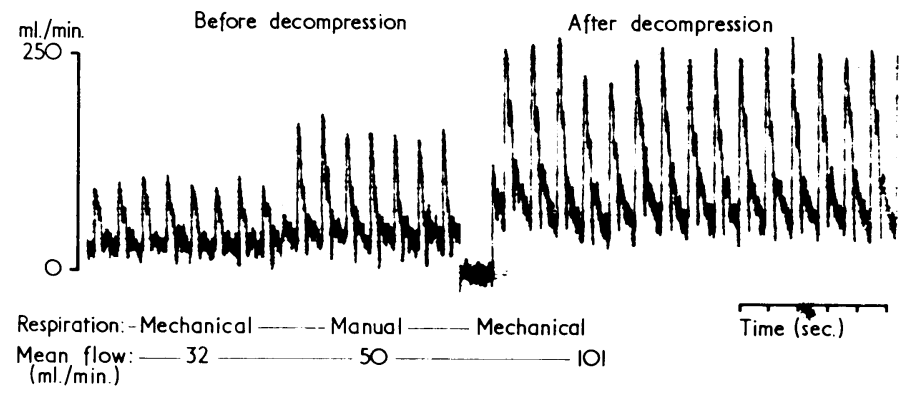

FIG. 3.-Case 5. Operative blood flow studies. Note increased flow in hepatic artery after decompression.

More recently his epigastric pain had altered in character and he had diarrhoea. His epigastric bruit disappeared on inspiration. Flow studies at operation showed no respiratory variation. Mean flow in the hepatic artery on the respirator was $32 \mathrm{ml}$./min., but this could be raised to $50 \mathrm{ml} . / \mathrm{min}$. by increasing the tidal volume on manual respiration. Post-decompression flow was $101 \mathrm{ml} . / \mathrm{min}$. on the respirator-a threefold increase (Fig. 3). In spite of this, however, his symptoms were unimproved and a faint bruit persisted. Repeat angiography showed a completely normal coeliac axis. Unfortunately he developed a popliteal occlusion subsequent to this investigation.

Case 6.-Pain in this woman was epigastric, related to food, and associated with loss of weight. Her bruit disappeared on inspiration and her angiogram was typical. She refused operation. 
Case 7.-Episodic epigastric pain with vomiting followed appendicectomy at the age of 7 . Though he had a typical bruit and angiogram he was thought to have a psychological overlay and was not offered surgery. He has subjectively improved on follow-up.

\section{Incidence of Bruits and Dyspepsia in Volunteers}

In 100 male and 100 female randomly selected volunteer hospital personnel aged 17 to 30 the epigastrium was auscultated without compression, with the subject supine. Only localized murmurs that were not conducted out of the epigastrium were noted, and these were usually in midepigastrium. The results are shown in 'Table II. In each sex one subject had a murmur while breathing quietly, which increased on expiration. Four women and six men had murmurs only in expiration and one man on inspiration.

TABLE II.-Epigastric Bruits and Dyspepsia in Normal Volunteers (Aged 17-30)

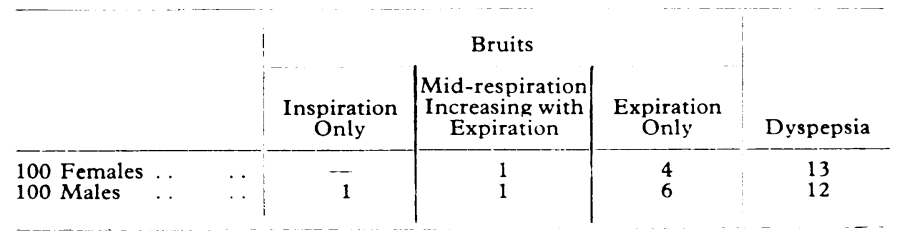

All subjects were questioned about dyspepsia, and 12 men and 13 women admitted to regular postprandial pain or discomfort. One man had a peptic ulcer. Of the six who could remember the effect of inspiration four said it made the pain worse. Only one subject with dyspepsia had a murmur.

\section{Discussion}

Of the 61 reported cases that had been submitted to surgery in five centres, 59 were followed up : $47(79.6 \%)$ were rendered asymptomatic, $8(13.6 \%)$ improved, and $4(6.8 \%)$ unimproved. Of our five cases two were asymptomatic and three unimproved. In spite of these poor clinical results direct measurement at operation had shown that the abnormal flow had been abolished by surgery. The opposite effect of respiration in Cases 2 and 3 on blood flow correlates with preoperative murmur variations and indicates that inspiration was associated with the partial opening of a totally occluded coeliac axis in Case 2 and the relief of a partial obstruction in Case 3, suggesting, perhaps, that the former was a more severe example of the latter. In Case 2 a "steal" situation was found in which reverse of blood flow in the hepatic artery indicated that the coeliac axis was "stealing" blood from the superior mesenteric via the gastroduodenal during inspiration. This woman was cured by surgery. In Case 3 a flow study showed that the intermittent obstruction to the coeliac axis induced a situation of hyperaemic flow.

Altered flow patterns in either of these two ways, if generally applicable, would allow this unique situation of intermittent visceral artery obstruction to give rise to symptoms on a vascular basis, without violating the previously held view that the collateral potential of the visceral bed required more than one artery (or its equivalent) to be lost before ischaemia is provoked (Dick et al., 1967; Rob, 1967). The collateral around the coeliac axis is particularly rich, and Michels (1955) cited 26 possible collateral pathways to the liver, other than the typical coeliac axis supply, and at least 16 of these are relevant to obstruction at its origin. It is just possible that chronic hyperaemia or a steal situation, insufficient to develop collaterals, might provoke symptoms. In two of our three failures, however, major improvement in circulation was demonstrated rheologically and normal postoperative angiograms showed relief of stenosis. In one a residual stenosis of $25 \%$ of the diameter of the axis had disappeared angiographically within six weeks, a finding contrary to the opinions of Lord et al. (1968).

Alternatively, symptoms might not be ischaemic in origin but might arise from fibrosis of or pressure on the coeliac ganglion or plexus as suggested by Harjola (1963). The coeliac nerve plexus might merely mediate or transmit pain sensation arising elsewhere. In either case postoperative relief might depend on division of nerve fibres, as a neurectomy, and be unrelated to haemodynamic factors, though this possibility has been denied by Marable et al. (1968). The brilliant results obtained by Lord et al. (1968), who undertook proximal coeliac axis resection, might find explanation in the wider and cleaner dissection necessary around that artery in preparing for arterial suture. Snyder et al. (1967) claimed 100\% success in five cases in which they attributed coeliac artery narrowing to the coeliac plexus, and it is reasonable to suppose that corrective surgery would be directed towards division of these nerves. That this nervous plexus is important in mediating mesenteric pain was shown in a patient whose abdominal pain of subsequently lethal small-bowel infarction was relieved by coeliac sympathetic local anaesthetic block (Sedlacek and Bean, 1957). It is perhaps relevant that the two patients who became asymptomatic in the present series had a more extensive clearance of the coeliac axis-aortic junction, the one in an assessment for direct arterial surgery, the other because of bleeding from an inferior phrenic artery that took origin from the coeliac. There is a possible parallel of relief of visceral pain by autonomic neurectomy in the treatment of angina pectoris by upper thoracic sympathectomy (White and Bland, 1948; Lindgren, 1950; Burnett and Evans, 1956; Palumbo and Lulu, 1963; Birkett et al., 1965).

Marable et al. (1968), who have the largest series of cases (30), suggest that the best results are to be expected in young women with postprandial epigastric pain as the dominant symptom, and it was for this reason that volunteers studied were in the younger age group. Neither Case 4 nor Case 5 fulfils these criteria, and both did poorly. Two other groups, however, (Lord et al., 1968; Harjola and Lahtiharju, 1968), describe similar cases that did well. Two of our patients (Cases 4 and 7) had cause for psychogenic symptoms of which we were aware, and the postoperative symptoms in Case 3 appeared to have a large psychogenic element that might well reflect on her preoperative symptoms. Drapanas and Bron (1966) reported similar experiences in two of a series of 17 cases on which operations were performed and pointed out the high incidence of psychiatric abnormality associated with this type of patient.

The frequency of epigastric bruits $(6.5 \%)$ in our volunteer group was less than that reported by Julius and Stewart (1967), who detected a murmur in $16 \%$ of a similar group of 170. Of the 13 in our group with bruits only one had dyspepsia $(7 \%)$, and of the 25 dyspeptics only one had a murmur $(4 \%)$. The frequency of dyspepsia in the whole group was $12.5 \%$. Thus these small figures provide no evidence that the incidence of bruits is higher in young persons with dyspepsia than in those without, and therefore give no support to the claim that a condition associated with a bruit is a cause of dyspepsia in this group. Nor is there a close relationship between epigastric bruit, symptoms, and angiographic abnormality, since there are reports of bruits and normal angiograms (Dunbar et al., 1965; Marable et al., 1966) and of arteriographic abnormality with no attributable symptoms (Reuter and Olin, 1965; Drapanas and Bron, 1966; Meaney and Kistner, 1967; Marable et al., 1968), though in the present series when the arterial compression was diagnosed clinically it was confirmed radiologically. There is therefore a real problem concerning the indication for angiography as an investigative procedure for dyspepsia with epigastric bruit, and a parallel may be drawn with that of renal artery stenosis and hypertension. Whereas DeBakey et al. (1964) reported a cure 
rate of $81 \%$ from arterial surgery in renal artery stenosis, Chamberlain and Gleeson (1965) pointed out that of all cases submitted to diagnostic arteriography only $4 \%$ received eventual surgical benefit, whereas $22 \%$ suffered significant morbidity, and they doubted the benefit of undertaking the original arteriogram. In our group of seven cases with positive angiograms only two were cured surgically and one other had the complication of popliteal occlusion.

\section{Conclusion}

Our experience with a small series of patients with coeliac axis compression has not been as sanguine as that of the previously larger series, but we feel it is important to report this in order to sound a note of caution lest patients become indiscriminately exposed to hazards, both operative and angiographic, in the expectation of the cure of their chronic abdominal pain. We feel that the validity of the syndrome and the efficacy of its treatment need further assessment before either can be unreservedly accepted into routine clinical practice.

We wish to thank the Board of Governors of St. Bartholomew's Hospital for financial support.

REFERENCES

Birkett, D. A., Apthorp, G. H., Chamberlain, D. A., Hayward, G. W., and Tuckwell, E. G. (1965). British Medical fournal, 2, 187.
Burnett, C. F., and Evans, J. A. (1956). fournal of the American Medical Association, 162, 709

Chamberlain, M. J., and Gleeson, J. A. (1965). Lancet, 1, 619.

DeBakey, M. E., Morris, G. C., Morgen, R. O., Crawford, E. S., and Cooley, D. A. (1964). American Fournal of Surgery, 107, 84

Deutsch, V. (1968). Clinical Radiology, 19, 309.

Dick, A. P., Graff, R., Gregg, D. McC., Peters, N., and Sarner, M. (1967). Gut, 8, 206.

Drapanas, T., and Bron, K. M. (1966). Annals of Surgery, 164, 1085

Dunbar, J. D., Molnar, W., Beman, F. F., and Marable, S. A.' (1965). American fournal of Roentgenology, Radium Therapy, and Nuclear Medicine, 95, 731 .

Edwards, A. J. (1969). Proceedings of the Royal Society of Medicine, $62,488$.

Harjola, P. T. (1963). Annales Chirurgiae et Gynaecologiae Fenniae, 52,

Harjola, P. T., and Lahtihariu, A. (1968). American fournal of Surgery, $115,864$.

Julius, S., and Stewart, B. H. (1967). New England fournal of Medicine, 276, 1175

Lindgren, I. (1950). Acta Medica Scandinavica, Suppl. No. 243.

Lord, R. S. A., Stoney, R. J., and Wylie, E. J. (1968). Lancet, 2, 795.

Marable, S. A., Kaplan, M. F., and Beman, F. M. (1968). American Fournal of Surgery, 115, 97

Marable, S. A., Molnar, W., and Beman, F. M. (1966). American fournal of Surgery, 111, 493.

Meaney, T. F., and Kistner, R. L. (1967). Archives of Surgery, 94, 811 .

Michels, N. A. (1955). Blood Supply and Anatomy of the Upper Abdominal Organs. Philadelphia, Lippincott.

Palumbo, L. T., and Lulu, D. J., (1963). Surgery, 53, 563.

Reuter, S. R., and Olin, T. (1965). Radiology, 85, 617.

Rob, C. (1967). American fournal of Surgery, 114, 363.

Sedlacek, R. A., and Bean, W. B. (1957). Annals of Internal Medicine, 46, 148 .

Snyder, M. A., Mahoney, E. B., and Rob, C. G. (1967). Surgery, 61, 372 .

Sutton, R. A. L. (1967). Proceedings of the Royal Society of Medicine, $60,139$.

White, J. C., and Bland, E. F. (1948). Medicine, 27, 1.

\section{Defibrination Syndrome due to Scorpion Venom Poisoning}

\section{SITA DEVI, ${ }^{*}$ M.B., B.S., M.SC. ; C. NARASIMHARA REDDY, $\dagger$ M.B., в.s. ; S. LAKSHMI DEVI, $\dagger$ M.B., в.s., D.c.P.; Y. R. SUBRAHMANYAM, $\ddagger$ H. VENKATAKRISHNA BHATT, $\$ M.sc. ; G. SUVARNAKUMARI, $\|$ M.B., B.s. ; D. PRASANTHA MURTHY, M.B., B.S. ; C. R. R. M. REDDY,** M.D.}

\begin{abstract}
Summary: Disseminated intravascular coagulation $\checkmark$. occurred in dogs given scorpion venom subcutaneously in doses of $3 \mathrm{mg}$. $/ \mathrm{kg}$. body weight. Treatment with heparin reversed the coagulation abnormality of the syndrome and 10 out of 12 dogs survived. Necropsy findings in human patients stung by scorpions suggest that this syndrome also occurs in man.
\end{abstract}

\section{Introduction}

This study was prompted by the finding that the sting of the scorpion often proved fatal in children and adults within 24 to 48 hours. Necropsy examinations carried out on four children and three adults who died of scorpion venom poisoning showed congestion in all the organs. Subendocardial haemorrhages were present in two, mural thrombosis of the heart in one, and massive haemorrhage of the adrenals in one and of the frontal lobe in another. There were pinpoint haemorrhages in the cerebral cortex. Histological examination

\footnotetext{
* Professor of Biochemistry.

+ Tutor in Biochemistry.

$\ddagger$ Demonstrator, Department of Biochemistry.

Assistant Research Officer, Department of Pharmacology.

Tutor in Pathology.

I Assistant Research Officer, Department of Pathology.
** Professor of Pathology.

Kurnool Medical College, Kurnool, S. India.
}

showed occlusions of small blood vessels with thrombi in the heart, lungs, brain, kidneys, and adrenals, which indicated disseminated intravascular coagulation resulting in defibrination and consequent haemorrhages.

\section{Materials and Methods}

The venom used was from a scorpion of the species Buthus tamulus, which is very common in Kurnool, a part of Rayalaseema from which this study is reported. Venom was extracted from the telson by means of a six-volt electric shock (Deoras, 1960). Drops of venom issuing from the sting were collected in a previously weighed glass test-tube. The contents of the tube were diluted with a known volume of distilled water. Fresh venom was used throughout the study. Clotting-time (Lee and White, 1913), prothrombin time (Quick, 1935), serial thrombin time (Brodsky et al., 1968), euglobulin lysis time (Cash, 1966), platelet count (Dameshek, 1932), and fibrinogen levels (Devi and Naganna, 1969) were estimated.

Preliminary experiments carried out on six dogs showed that the venom in doses of $0.75 \mathrm{mg} . / \mathrm{kg}$. injected subcutaneously had no effect at all, doses of $2.5 \mathrm{mg}$. $/ \mathrm{kg}$. had some effect, but doses of $3 \mathrm{mg} . / \mathrm{kg}$. had the maximum effect and invariably killed the dogs in two to four hours. Similarly, 25mg. doses of heparin given intramuscularly to four dogs in a 